\title{
Biospecimen Events Domain
}

National Cancer Institute

\section{Source}

National Cancer Institute. Biospecimen Events Domain. NCI Thesaurus. Code C111138.

An events domain that documents biospecimen collection and storage information. 